\title{
Battery Charger Utilizing Coupled Inductor Based High Gain Bidirectional DC-DC Converter: Analysis, Design, and Implementation
}

\author{
Mahamdasraf A. Mulla*, Vishal J. Dobariya, Rajan V. Vamja, Arindam Sircar \\ Department of Electrical Engineering, Sardar Vallabhbhai National Institute of Technology, Surat, Gujarat 395007, India
}

Corresponding Author Email: mamulla@ieee.org

https://doi.org/10.18280/ejee.230302

Received: 4 July 2020

Accepted: 29 April 2021

\section{Keywords:}

battery charging, bidirectional DC-DC converter, high voltage gain, coupled inductor

\begin{abstract}
The bidirectional dc-dc converter with high voltage gain and high efficiency plays an important role in the designing of battery charging systems. In this paper, design and development of a battery charging system utilizing coupled inductor based high gain dcdc converter is presented. The converter uses a clamp capacitor network to recover the leakage energy of a coupled inductor. The converter has inherent soft-switching capability during turn ON, which ensures high efficiency at high switching frequency. Design equations to derive value of different passive components are given and a step-wise exclusive design to construct coupled inductor is presented. A $50 \mathrm{kHz}, 500 \mathrm{~W}$ laboratory prototype has been designed, which can increase the voltage with 10 gain (boost operation) in one direction and can reduce the voltage at (1/10) gain (buck operation) in other direction. The CCCV battery charging algorithm is implemented using generic ARM Cortex-M4 microcontroller. Extensive experiments have been performed and the experimental results are presented in buck, boost, and battery charging operations.
\end{abstract}

\section{INTRODUCTION}

Due to the intermittent nature of renewable sources, secondary storage device like batteries have become indispensable in many applications. Batteries are an essential part of many power electronic applications like AC-DC microgrids, elevators, electric vehicles, etc. [1,2]. A major technical challenge arises in interfacing batteries with system voltages due to the difference in the level of voltage ratings between them. Design of power electronic converters with required high step-up or step-down gain becomes an important aspect [3, 4]. Therefore, the interfacing circuits in such applications require a DC-DC converter with bidirectional power flow and high voltage conversion ratio. Batteries have limited charge-discharge life period $[5,6]$. It is therefore required to charge them with constant-current (CC) or constant-voltage $(\mathrm{CV})$ by knowing the state of charge of the batteries. The control of power electronic converters for photovoltaic applications is another task. Some control strategies using Artificial Neural Networks and Fuzzy logic control have been studied by Fapi et al. [7], Jayaraju and Rao [8]. The performance analysis of different controllers for hybrid energy systems has been shown by Katuril and Gorantla [9, 10].

The efficiency of conventional BDC reduces drastically when operated with high duty cycle to achieved HV conversion ratios [11]. This is because of practical circuit drops like device drops, drop due to equivalent series resistance (ESR) of inductor, capacitor etc. The efficiency of such BDC declines with low or higher duty cycle, thereby limiting its conversion ratio [12]. The application of such BDC is limited in battery charging as it cannot achieve HV conversion ratios efficiently. Several BDCs are proposed to achieve energy efficient HV conversion. They are based on high frequency transformer, coupled inductor, switching capacitor, switching inductor, voltage lift technique, voltage multiplier technique etc. [13-16].

In high-frequency transformer based BDC topologies, the turns ratio of the transformer provides the HV conversion [17]. The topologies based on dual active bridge are evolved as higher voltage gain bidirectional DC-DC converter configurations. These topologies involve a large number of switches resulting in high switching loss, which can be reduced by using soft-switching schemes presented by Yang and Do [18]. However, this leads to complex configurations and control. It is also required to protect the switches against $\mathrm{HV}$ spikes resulting from the leakage inductance of the isolation transformer. Snubber circuits are utilized to limit these voltage spikes. A snubber capacitor stores the leakage energy during the turn OFF time of switch. This energy is dissipated in the snubber resistor or retrieved by recycling it. Recycling energy requires an active clamping circuit having additional switches and an extra transformer, which makes the BDC bulky and complex [19]. Non-isolated BDC topologies derived from flyback and forward converters have been researched but their implementation is limited to low-power applications [20,21]. BDCs based on a switched capacitor have also been researched by Amjadi and Williamson [22]. These arrangements required large number of switches and capacitors for HV conversion, which makes the circuit complicated. The voltage multiplier-based topology needs several cells with high rating, which results in high voltage stresses on the components. Switched inductor and voltage lift technique is not suitable for high power application as it requires a large number of passive components.

In another approach, for HV conversion using BDC, coupled inductor-based topologies are proposed by Hsieh et al. [23]. These converters have less circuit components as 
compared to the prior transformer and switched capacitor-based topologies. Bipolar core excitation is also possible in these converters, which make them suitable for high-power and high efficiency applications. However, in these arrangements as well, the presence of leakage energy necessitates the use of a clamp capacitor network for the safe operation of switches. High voltage gain of such configurations can be increased with an intermediate capacitor at the secondary of the coupled inductor. Many topologies of coupled inductor based BDC with clamped capacitor have been studied to minimize the numbers of circuit components. Out of them, the BDC proposed by Shreelakshmi et al. [24] has fewest components, i.e., a coupled inductor, a clamp and an intermediate capacitor, and four power electronics switches. In this topology, the efficiency is improved by recovering the leakage energy in the clamp capacitor. All switches achieve an inherent softswitching during turn $\mathrm{ON}$, which reduces switching losses and increases efficiency.

In summary, high gain dc-dc converters are essential for interfacing low voltage source with high voltage dc link in the distributed generation environment [25]. The key objective of the presented study are as follows:

1) To develop a charging circuit to charge the lead acid and/or lithium-ion batteries. Accordingly, the constant current (CC) and constant voltage (CV) charging methods are implemented.

2) The real time implementation of the coupled inductor based, soft switched, high gain BDC for battery charging application is presented. The complete design steps of the selected converter are demonstrated.

3) The high voltage gain is achieved through the use of a coupled inductor and an intermediate capacitor. The topology ensures ZVS during turn-on for all active switches over the entire battery charging range, which enhances the efficiency.

4) The control circuit of the converter is realized using generic low-cost ARM Cortex-M4 microcontroller STM32F407VG from ST Microelectronics.

5) The converter is designed at $50 \mathrm{kHz}$ high switching frequency, which makes the size of the converter compact. Also, the use of general-purpose microcontroller makes the converter cost effective.

\section{CIRCUIT DESCRIPTION}

The implemented high gain BDC consists of a coupled inductor, four switches, a clamp and an intermediate capacitor. The leakage energy is recovered using the clamp capacitor, which improves efficiency. The coupled inductor and intermediate capacitor are utilized to achieve the high voltage gain. At the secondary of the coupled inductor, the intermediate capacitor is charged in series and discharged in parallel during buck operation. The operation is vice versa during the boost mode. The converter has soft switching capability for all switches.

The circuit schematic of the implemented BDC for the battery charging application is shown in Figure 1. The circuit consists of two capacitors and one coupled inductor. $C_{1}, C_{2}$ are a clamp capacitor and an intermediate capacitor, respectively. There are four switches $\left(S_{1}-S_{4}\right)$ along with anti-parallel body diodes $\left(D_{1}-D_{4}\right) . L_{1}$ and $L_{2}$ are the inductances of the low voltage (LV) and high voltage (HV) windings of the coupled inductor, respectively.
In the presented DC-DC converter, the leakage energy in the coupled inductor is recovered using the clamp capacitor $C_{1}$. Due to the recycling of this leakage energy, the losses are less and efficiency is higher in the BDC. The voltage spikes across the switches are also reduced and the converter becomes more reliable. $C_{2}$ is used for an intermediate energy storage which helps to increase the voltage conversion ratio. Due to the higher voltage conversion ratio and the ZVS capability of the switches, the presented BDC is a suitable choice for battery charging application. The operation of the presented BDC is explained for boost and buck modes in subsequent sections.

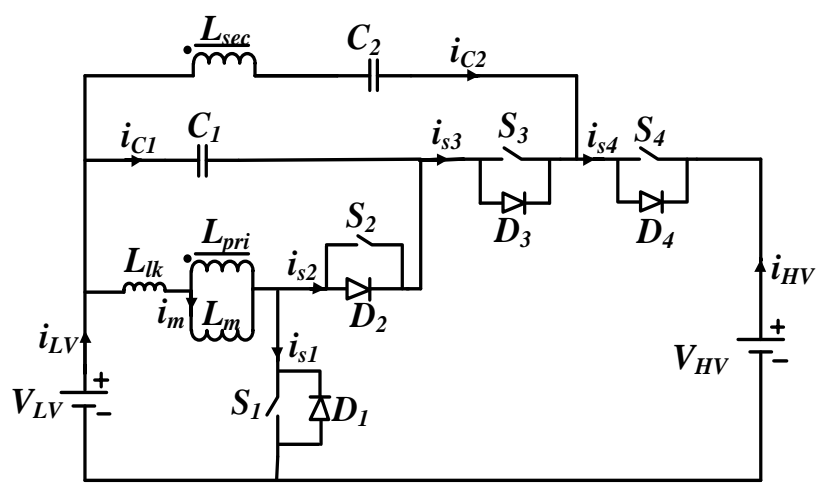

Figure 1. Circuit configuration of implemented high gain bidirectional DC-DC converter

\subsection{Boost mode of operation}

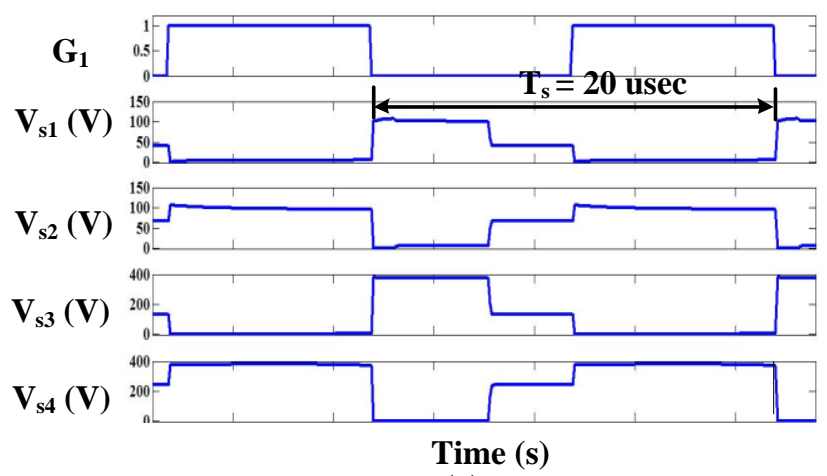

(a)

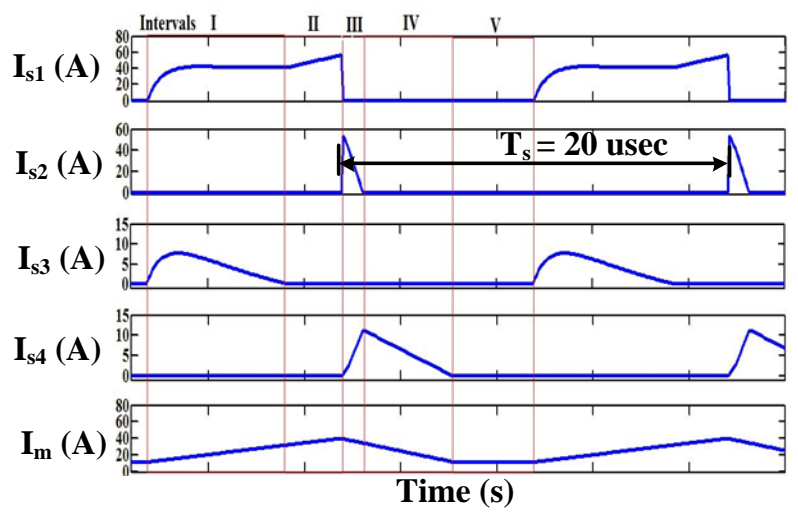

(b)

Figure 2. Steady-state waveforms in boost mode: (a) gate pulses and voltage across switches; and (b) current through different switches 


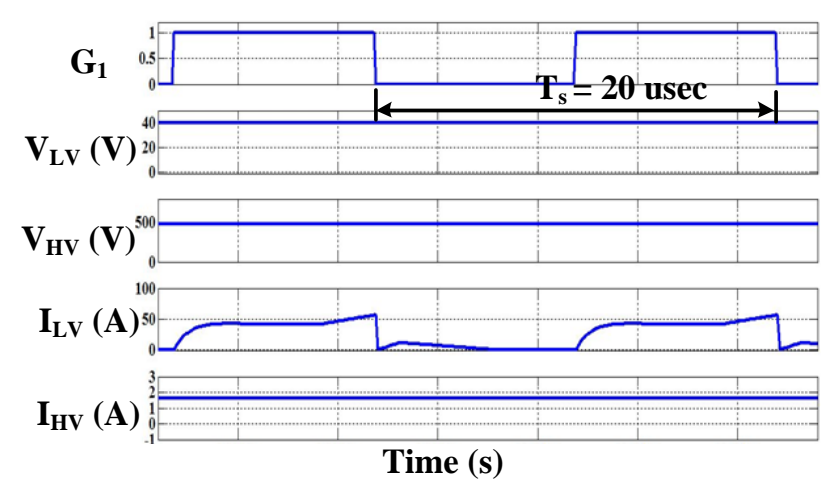

Figure 3. Steady-state waveform of input-output parameters of presented BDC during boost mode: $V_{L V}, V_{H V}, I_{L V}$, and $I_{H V}$

The boost mode of operation is divided into five intervals as shown in Figure 2 and Figure 3. Figure 2 shows the steadystate waveforms of the current through and the voltage across all switches. Figure 3 shows the steady-state waveforms of the current through and the voltage across the inductor. During interval I, switch $S_{1}$ is turned ON. The current flows from the battery to the coupled inductor. Energy is stored in the magnetizing inductance of the coupled inductor and the capacitor $C_{2}$ through the secondary winding of the coupled inductor and the capacitor $C_{1}$. The body diode $D_{3}$ is forward biased due to the induced voltage in the coupled inductor. In Interval II, current through $D_{3}$ becomes zero. The current through $S_{1}$ increases linearly. This interval ends when $S_{1}$ is turned OFF.

During interval III, $D_{2}$ is forward biased due to the energy stored in the leakage inductance and the charge of the clamp capacitor $C_{l}$. Additionally, during this interval the stored coupled inductor energy is transferred to the load through the inductor $L_{2}$, the capacitor $C_{2}$, and the diode $D_{4}$. The interval ends when the current flowing in $D_{2}$ becomes zero. During interval IV, $D_{2}$ turns OFF and $D_{4}$ continues to conduct. This interval ends when the current through $D_{4}$ becomes zero. In interval $\mathrm{V}$, none of the switches are in conduction.

Interval $\mathrm{V}$ ends when $\mathrm{S}_{1}$ is turned $\mathrm{ON}$. From the steady-state analysis, the voltage gain equation for boost mode can be written as:

$$
\frac{V_{H V}}{V_{L V}}=\frac{n+1}{1-D}
$$

where, $V_{H V}, V_{L V}$ are the high voltage and low voltage side voltages, respectively. $n$ is turns ratio of the coupled inductor. $D$ is the duty cycle of switch $S_{l}$.

\subsection{Buck mode of operation}

The buck mode of operation is divided into six different intervals as shown in Figure 4. The voltage and current waveforms of all the switches are observed in Figure 4 whereas the voltage and the current waveforms of the coupled inductor are shown in Figure 5. In interval I, $S_{2}$ is turned ON, and current flows from $C_{1}$ to the primary winding of the coupled inductor. In this interval, the body diode of $S_{4}$ starts to conduct when $S_{4}$ is triggered. ZVS is observed during turn ON of $S_{4}$ as shown in Figure 4(b). In interval II, only switch $S_{4}$ conducts and energy is stored in the coupled inductor through the secondary winding. This interval is similar to the turn ON mode of the conventional buck converter. This interval ends when $S_{4}$ is turned OFF.

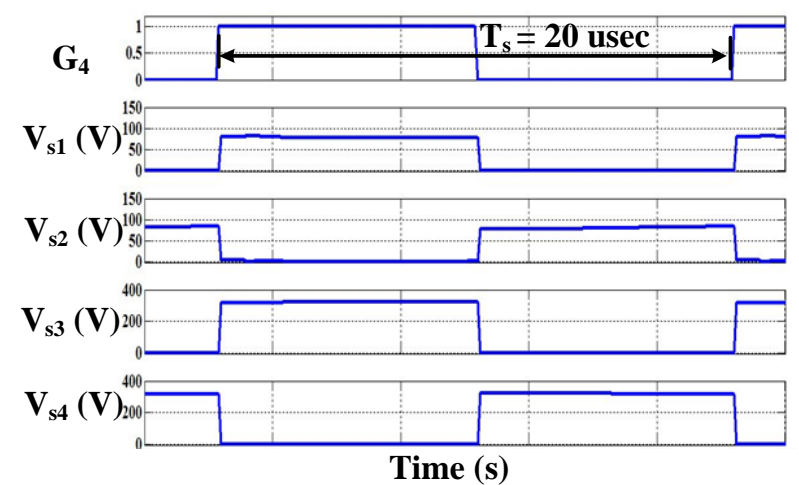

(a)

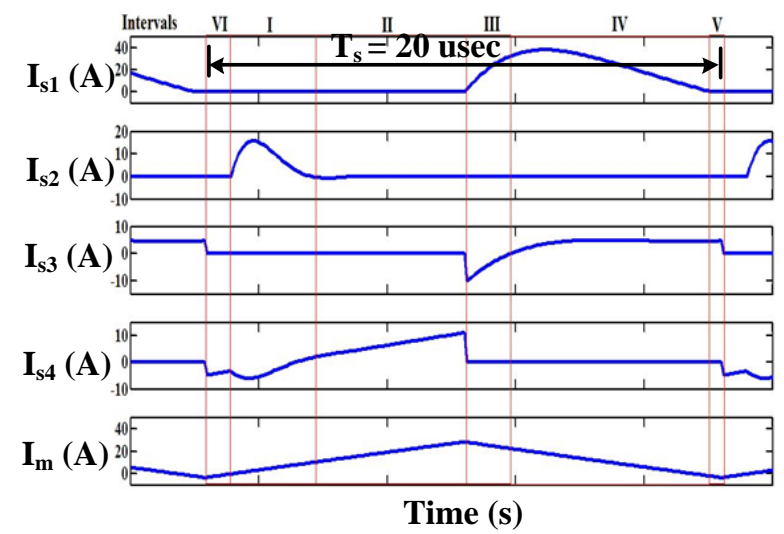

(b)

Figure 4. Steady-state waveforms in buck mode: (a) gate pulses and voltage across switches; and (b) current through different switches

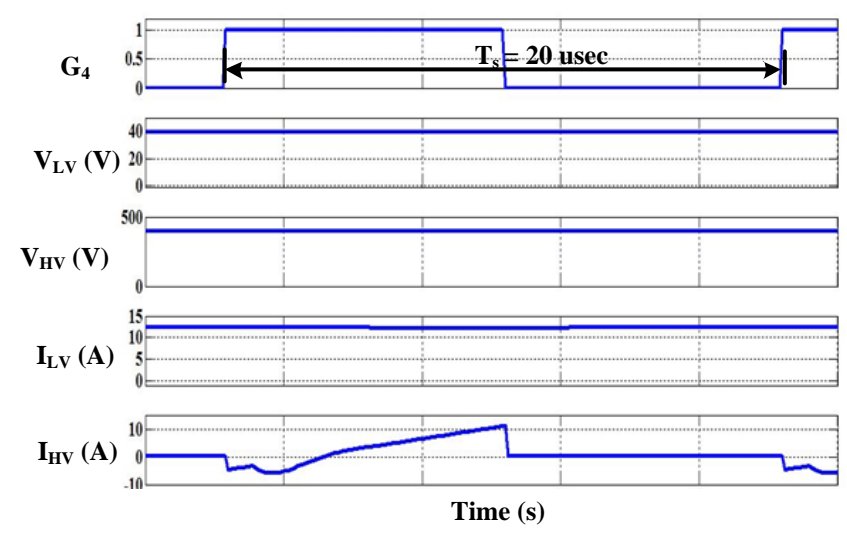

Figure 5. Steady-state waveform of input-output parameters of presented BDC during buck mode: $V_{L V}, V_{H V}, I_{L V}$, and $I_{H V}$

During interval III, all switches remain OFF, and the body diodes of $S_{3}$ and $S_{1}$ conduct. This interval ends when $S_{3}$ is turned ON. Since $D_{3}$ is already in conduction, ZVS is observed during turn $\mathrm{ON}$ of switch $S_{3}$. Interval IV starts with the turning ON of switch $S_{3}$. Energy is transferred from $C_{2}$ to $C_{1}$ through the secondary winding of coupled inductor.

The interval $\mathrm{V}$ begins when the current through $D_{l}$ becomes zero. Current through $S_{3}$ continues during interval V. This interval ends when $S_{3}$ is turned OFF. Due to turning OFF of $S_{3}$, 
the current through secondary of the coupled inductor forces the body diode of switch $S_{4}$ to turn ON. Interval VI starts with the turning ON of diode $D_{4}$. This interval ends when $S_{4}$ is triggered. From the steady-state analysis, the voltage gain equation for buck mode can be written as:

$$
\frac{V_{L V}}{V_{H V}}=\frac{D}{1+n}
$$

where, $D$ is the duty cycle of switch $S_{4}$.

The design of the various circuit components of presented high gain DC-DC converter is explained in the next section.

\section{DESIGN OF CIRCUIT COMPONENTS}

In this section, the design of various circuit components is described. The presented BDC is designed for the ratings given in Table 1. The coupled inductor is designed such that it allows for $10 \%$ current ripple in currents. Additionally, all the capacitors have been designed to limit voltage ripple to $0.1 \%$ of rated voltage.

Table 1. Ratings considered for design of different components of BDC

\begin{tabular}{cc}
\hline Parameters & Values \\
\hline Power & $500 \mathrm{~W}$ \\
\hline $\mathrm{V}_{\mathrm{HV}}$ & $400 \mathrm{~V}$ \\
\hline $\mathrm{V}_{\mathrm{LV}}$ & $40 \mathrm{~V}$ \\
\hline $\mathrm{f}_{\mathrm{sw}}$ & $50 \mathrm{kHz}$ \\
\hline Voltage Ripple & $0.1 \%$ \\
\hline Current Ripple & 10 \\
\hline
\end{tabular}

\subsection{Design of coupled inductor}

The design of coupled inductor is essential for the BDC. For CCM operation, turns ratio $n$ and duty cycle $D$ is obtained using Eq. (1) and Eq. (2) for boost mode and buck mode, respectively.

For DCM operation, voltage gain of the presented BDC in boost mode is expressed as:

$$
\frac{V_{H V}}{V_{L V}}=\frac{1+n}{2}+\frac{\sqrt{(1+n)^{2}+\frac{2 D^{2} T_{S} R_{L V}}{L_{l}}}}{2}
$$

where, $R_{L V}$ is the low voltage side load resistance. $T_{s}$ is the switching period. $L_{l}$ is the primary side inductance value of the coupled inductor.

The critical inductance of primary winding of coupled inductor $L_{\text {lcrit }}$ is obtained by equating Eq. (1) and Eq. (3). This is expressed as:

$$
\frac{L_{\text {lcrit }}}{T_{S} R_{H V}}=\frac{(1-D)^{2} D}{2(1+n)^{2}}
$$

where, $R_{H V}$ is the HV side load resistance. $L_{l}$ is the primary side inductance value of the coupled inductor.

The critical inductance of secondary winding $L$ is obtained using the following equation:

$$
L_{2 c r i t}=n^{2} L_{1 c r i t}
$$

where, $L_{\text {Icrit }}$ is the primary side critical inductance.

The practical values of inductors $\left(L_{1}\right.$ and $\left.L_{2}\right)$ are selected as approximately 3 times the critical values for CCM operation. Accordingly, it is calculated to be $45 \mu \mathrm{H}$ and $720 \mu \mathrm{H}$ for $L_{l}$ and $L_{2}$, respectively.

\subsection{Design of capacitors}

Designs of different capacitors are given in following subsections.

\subsubsection{Design of the capacitor $\mathrm{C}_{\mathrm{HV}}$}

During interval I of boost mode, $C_{H V}$ supplies the load current and its value is calculated as:

$$
C_{H V}=\frac{I_{H V} D}{f_{s w}(0.001) V_{H V}}
$$

where, $I_{H V}$ is the high voltage side source current. $f_{s w}$ denotes the switching frequency.

By considering the coupled inductor current ripple, the value of capacitor $C_{H V}$ is selected as:

$$
C_{H V}=\frac{\left(\frac{n+1}{1-D}-1\right) V_{L V}}{8 L_{m} f_{s w}^{2}(0.001) V_{H V}}
$$

where, $L_{m}$ is the magnetizing inductance of coupled inductor.

To minimize voltage ripple, higher value amongst Eq. (6) and Eq. (7) is selected.

\subsubsection{Design of the capacitor $\mathrm{C}_{\mathrm{LV}}$}

The capacitor $C_{L V}$ is utilized to filter out inductor current ripple. Based on the ripple current magnitude, the minimum value of the capacitance is calculated as:

$$
C_{L V}=\frac{1-\left(\frac{D}{1+n}\right) V_{L V}}{8 L_{m} f_{s w}^{2}(0.001) V_{L V}}
$$

The capacitor $C_{L V}$ also supplies current during the buck operation. Hence, it is evaluated as:

$$
C_{H V}=\frac{I_{L V} D(0.05)}{f_{s w}(0.001) V_{L V}}
$$

where, $I_{L V}$ is the low voltage side source current.

\subsubsection{Design of Capacitor $\mathrm{C}_{2}$}

This capacitor is charged in parallel with secondary winding during boost operation and is discharged in series with the secondary of the coupled inductor to obtain high conversion ratio. In buck mode, the opposite operation occurs.

$$
V_{C 2}=\frac{D(1-n)+n}{1-D} V_{L V}
$$

From Eq. (10), the average voltage across the capacitor can be obtained. For the ripple voltage of $0.1 \%$, The value of capacitor $C_{2}$ is calculated as: 


$$
C_{2}=\frac{I_{L V} D}{n f_{s w}(0.001) V_{C 2}}
$$

3.2.4 Design of the capacitor $\mathrm{C}_{1}$

From Eq. (12), the average value of voltage across $C_{l}$ is obtained for buck and boost operation as:

$$
V_{C l}=\frac{D V_{H V}}{1+n}
$$

In interval II for boost operation, and in interval IV of buck operation, the capacitor $C_{1}$ is charged and value is calculated as:

$$
C_{I}=\frac{I_{L V} D(0.05)}{f_{s w}(0.001) V_{C l}}
$$

The calculated values for $C_{H V}, C_{L V}, C_{2}$ and $C_{1}$ are $330 \mu \mathrm{F}$, $200 \mu \mathrm{F}, 50 \mu \mathrm{F}$ and $10 \mu \mathrm{F}$, respectively.

\subsection{Design of switches}

The switches are designed to carry RMS current when they are $\mathrm{ON}$ and withstand the average drain to source voltage across the switch when they are OFF. The RMS values of switches is observed during simulation study. The basic design equations are mentioned below.

The RMS value of current through the switch $S_{1}$ is calculated as:

$$
I_{S I r m s}=\frac{n V_{L V} T_{S} D \sqrt{D}}{L_{m} \sqrt{3}}
$$

The voltage across the switch $S_{1}$ is calculated as:

$$
V_{S I}=\frac{1}{1-D} V_{L V}
$$

The RMS value of current through the switch $S_{2}$ is calculated as:

$$
I_{S 2 r m s}=\frac{0.05^{1.5} V_{C 1} T_{S} D \sqrt{D}}{L_{l k} \sqrt{3}}
$$

The voltage across the switch $S_{2}$ is calculated as:

$$
V_{S 2}=\frac{1}{1-D} V_{L V}
$$

The RMS value of current through the switch $S_{3}$ is calculated as:

$$
I_{S 3 r m s}=\frac{V_{L V} T_{S} D \sqrt{D}}{L_{m} \sqrt{3}}
$$

The voltage across the switch $S_{3}$ is calculated as:

$$
V_{S 3}=2 n V_{L V}
$$

The RMS value of current through the switch $\mathrm{S}_{4}$ is calculated as:

$$
I_{S 4 r m s}=\frac{V_{L V} T_{S} D \sqrt{D}(1-D)}{(n+1) L_{1} \sqrt{3}}
$$

The voltage across the switch $\mathrm{S}_{4}$ is calculated as:

$$
V_{S 4}=\frac{n}{1-D} V_{L V}
$$

The rating of the switches for the BDC is shown in Table 2.

\subsection{Construction of coupled inductor}

This section presents the construction of the coupled inductor using the values of $L_{1}$ and $L_{2}$ as determined in Section 3.1 .

\subsubsection{Area product}

The amount of energy stored in a coupled inductor is calculated as:

$$
E_{L}=\frac{1}{2} L_{l} I_{m}^{2}
$$

where, $I_{m}$ is the maximum magnetizing current through the coupled inductor.

The current in the primary winding during CCM operation increases linearly during the turn ON time and decreases linearly during the turn OFF time. Hence, the average current through the equation is given by:

$$
I_{m}=I_{\text {Llavg }}+\frac{1}{2} \Delta I_{L 1}
$$

where, $I_{\text {Llavg }}$ is the average current through inductor and $\Delta I_{L I}$ is the ripple current through the inductor.

Using Eq. (22), the Area Product of the magnetic core is calculated by the following equation:

$$
A_{P}=A_{w} A_{C}=\frac{2 E_{L}}{K_{w} K_{c} J B_{m}}
$$

where, $A_{w}, A_{c}, K_{w}, K_{c}, B_{m}$ and $J$ are the window area of the core, the cross-sectional area of the core, the window space factor, the crest factor, the maximum flux density and the current density in the windings, respectively.

From Eq. (24), the minimum required Area Product for the core is calculated as $11253 \mathrm{~mm}^{4}$.

\subsubsection{Selection of core and permeance calculation}

The core to be selected should have an area product greater than the one calculated in Eq. (24). The permeance of the core is expressed as:

$$
\Lambda=\frac{\mu_{0} \mu_{r} A_{C}}{l_{m}+\mu_{r} l_{g}}
$$

where, $\Lambda, \mu_{r}, l_{m}, l_{g}$ are the permeance, the relative permeability, the magnetic path length and the air gap length, respectively.

Using Eq. (25), the calculated values of permeance of core is $442 \mathrm{nH} /$ turns $^{2}$.

\subsubsection{Calculation of number of turns}

The number of turns can be expressed in terms of permeance and inductance as: 


$$
N=\sqrt{\frac{Z}{\Lambda}}
$$

where, $N$ is the number of turns of the inductor.

The number of turns for primary and secondary windings are calculated as 10 and 40 , respectively.

\subsubsection{Wire gauge selection}

Selection of wire gauge is dependent on the current density of the material and current flowing through to it. The crosssection area of the wire is given as:

$$
a=\frac{I_{r m s}}{J}
$$

where, $a$ is the cross-sectional area of the wire, $I_{r m s}$ is the RMS current flowing through the wire and $J$ is the current density.

For the designed BDC, the current density of both primary and secondary windings is equal. The practical value of $a$ is approximated to the nearest value in the SWG table. The calculated value for $a_{1}$ and $a_{2}$ are $4.166 \mathrm{~mm}^{2}$ and $0.4166 \mathrm{~mm}^{2}$, respectively. Accordingly, the selected wire gauges are the SWG 13 and SWG 22.

\subsubsection{Check for window area available}

To accommodate the number of turns calculated using Eq. (26) with the wire gauge selected using Eq. (27), enough space should be available in the window to accommodate the turns. It is confirmed using the following inequality:

$$
A_{w} K_{w}>a_{1} N_{1}+a_{2} N_{2}
$$

All calculated parameters of circuit components are shown in Table 2. By considering the derived value of components for presented BDC, the experimental setup is constructed. The operation of the circuit is verified in boost and buck modes. Moreover, the CCCV battery charging operation is experimented using the designed BDC. The experimental results are discussed in the next section.

Table 2. Calculated value of different components

\begin{tabular}{cc}
\hline Component & Values \\
\hline Coupled Inductor: & \\
Duty Ratio (D) & 0.5 \\
Turns Ratio $(\mathrm{n})$ & 4 \\
Primary Turns $\left(\mathrm{N}_{1}\right)$ & 10 \\
Secondary Turns $\left(\mathrm{N}_{2}\right)$ & 40 \\
Primary Inductance $\left(\mathrm{L}_{1}\right)$ & 45 \\
Secondary Inductance $\left(\mathrm{L}_{2}\right)$ & 720 \\
Window Space Factor $\left(\mathrm{K}_{\mathrm{w}}\right)$ & 0.3 \\
Crest Factor $\left(\mathrm{K}_{\mathrm{c}}\right)$ & 1.05 \\
Current Density $(\mathrm{J})$ & $3 \times 10^{\wedge} 6$ \\
Maximum Flux Density $\left(\mathrm{B}_{\mathrm{m}}\right)$ & 0.8 \\
Area Product required $\left(\mathrm{A}_{\mathrm{p}}\right)$ & 11253 \\
Outer Diameter $\left(\mathrm{D}_{\mathrm{out}}\right)$ & 52 \\
Inner Diameter $\left(\mathrm{D}_{\mathrm{in}}\right)$ & 28 \\
Magnetic Path Length $\left(\mathrm{l}_{\mathrm{m}}\right)$ & 126 \\
Air Gap Length $\left(\mathrm{l}_{\mathrm{g}}\right)$ & 0 \\
Cross-Section Area of Core $\left(\mathrm{A}_{\mathrm{c}}\right)$ & 180 \\
Window Area of Core $\left(\mathrm{A}_{\mathrm{w}}\right)$ & 615 \\
Relative permeability $\left(\mu_{\mathrm{r}}\right)$ & 245 \\
Permeance of core $(\Lambda)$ & 442 \\
Cross Section Area of primary winding & $\mathrm{SWG} 13$ \\
Cross Section Area of secondary winding & $\mathrm{SWG} 22$
\end{tabular}

\section{Capacitors}

Input Capacitance $\left(\mathrm{C}_{\mathrm{HV}}\right)$

Output Capacitance $\left(\mathrm{C}_{\mathrm{LV}}\right)$

Clamp Capacitor $\left(\mathrm{C}_{1}\right)$

Intermediate Capacitor $\left(\mathrm{C}_{2}\right)$ Switches

$\begin{array}{lc}\mathrm{S}_{1} & 100 \mathrm{~V}, 15 \mathrm{~A} \\ \mathrm{~S}_{2} & 100 \mathrm{~V}, 15 \mathrm{~A} \\ \mathrm{~S}_{3} & 500 \mathrm{~V}, 5 \mathrm{~A} \\ \mathrm{~S}_{4} & 500 \mathrm{~V}, 5 \mathrm{~A}\end{array}$

\section{EXPERIMENTAL RESULTS AND DISCUSSION}

The experimental setup is constructed according to the block diagram shown in Figure 6(a). At the LV side, a leadacid battery rated $12 \mathrm{~V} 42 \mathrm{Ah}$ is connected whereas at the $\mathrm{HV}$ side, DC load of $320 \Omega$ and rectified DC voltage source are connected using contactor switches. The BDC consists of SiC MOSFETs (C3M0120090D) as the switches. Hall effectbased DC sensor cards (Nitech make) sense the battery voltage $\left(V_{\text {bat }}\right)$ and current $\left(\mathrm{I}_{\text {bat }}\right)$. These sensed signals are given to the microcontroller, which generates $50 \mathrm{kHz}$ PWM pulses $\left(\mathrm{G}_{1}-\mathrm{G}_{4}\right)$ according to the implemented control system. These pulses are processed though the driver card consisting of a TLP250 optocoupler, which provides optical isolation between the power circuit and control circuit. These isolated pulses drive the $\mathrm{SiC}$ switches of the designed BDC. The photograph of the experimental prototype is shown in Figure 6(b).

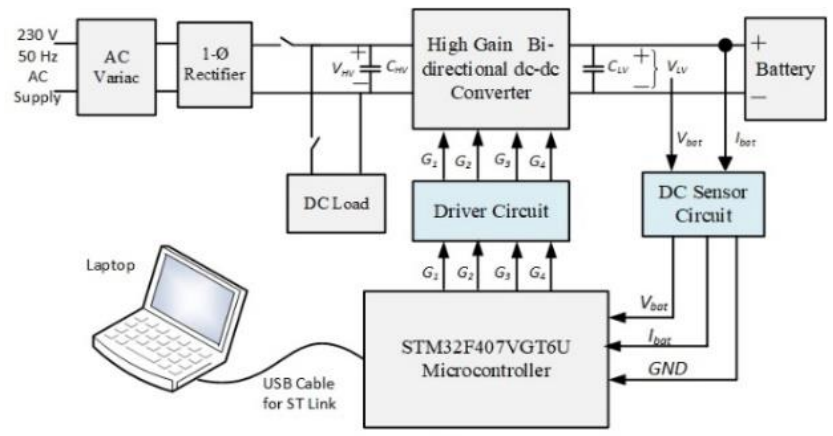

(a)

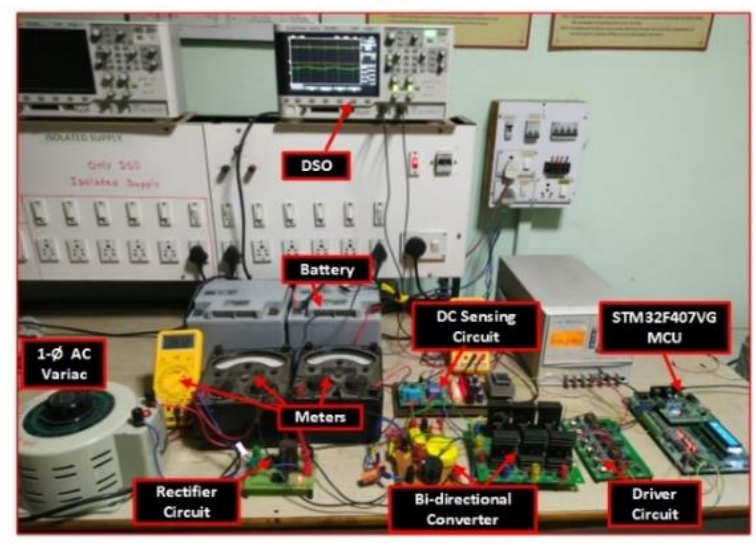

(b)

Figure 6. Experimental setup of high gain bidirectional DCDC converter: (a) block diagram; and (b) photograph of the prototype

The control is implemented using a general-purpose ARM Cortex-M4 32-bit microcontroller, STM32F407VG. Selected control operates at $168 \mathrm{MHz}$, and it has required on-chip 12bit analog to digital converter (ADC) and dedicated high- 
speed PWM timers. All the voltage and current values are measured utilizing two analog voltmeters and two digital voltmeters. During the experimentation, current and voltage waveforms are captured using a digital storage oscilloscope.

The experiment results are discussed next in three parts. The first and second part presents the performance of the designed BDC in boost mode and buck mode, respectively. These separate experiments are performed to verify the gain and switch voltage stress during the buck and boost mode of the operation. In the third part, the CCCV battery charging scheme is implemented, and results are discussed.

\subsection{Experimentation in boost mode of operation}

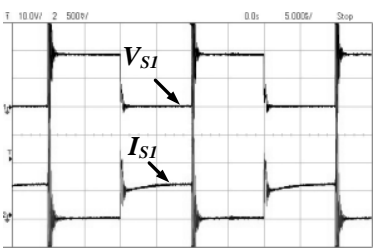

(a)

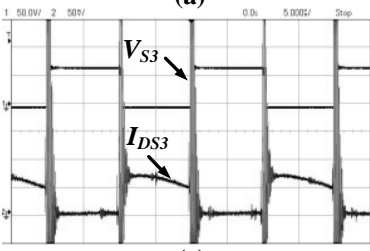

(c)

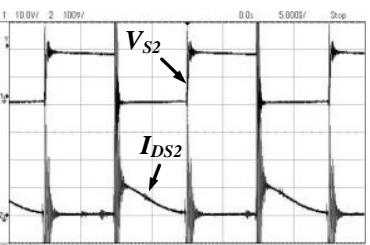

(b)

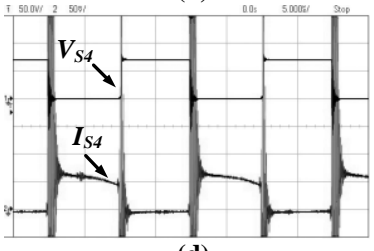

(d)
Figure 7. Steady-state waveform of switch voltage and switch current in boost mode: (a) $V_{S 1}, I_{S 1}$; (b) $V_{S 2}, I_{D S 2}$; (c) $V_{S 3}, I_{D S 3}$; and (d) $V_{S 4}, I_{S 4}$

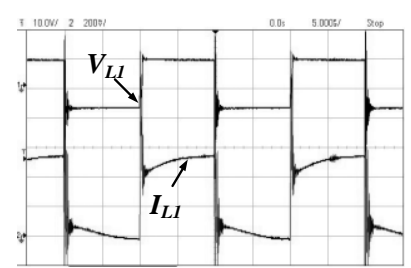

(a)

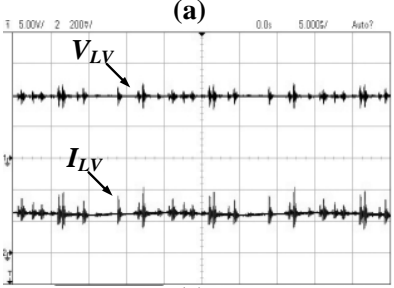

(c)

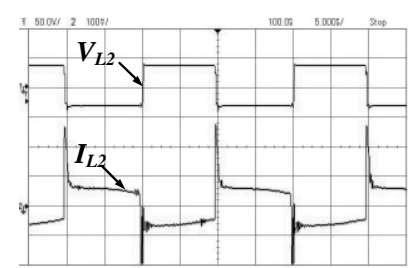

(b)

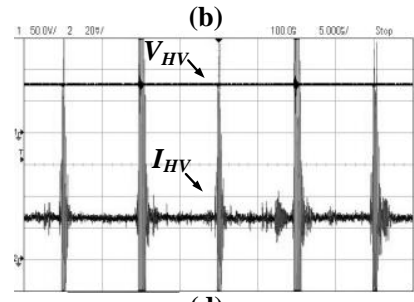

(d)
Figure 8. Steady-state waveform of voltage and current in boost mode: (a) primary winding: $V_{L l}, I_{L l}$; (b) secondary winding: $V_{L 2}, I_{L 1}$; (c) low voltage input: $V_{L V}, I_{L V}$; and (d) high voltage output: $V_{H V}, I_{H V}$

The experimental results of the boost mode are presented in this section. A $12 \mathrm{~V}$ battery is used as a source on the LV side of the BDC. On the HV side, a $320 \Omega$ rheostat is connected as a load. During boost operation, only switch $S_{1}$ is operated. Current and voltage waveforms of switch $S_{l}$ are shown in Figure 7(a). $S_{I}$ is ON in the interval I and II of boost operation. $S_{l}$ helps in storing energy from battery to coupled inductor through the primary winding. Figure 7(b) shows the current and voltage waveform of switch $S_{2}$. Current $I_{D S 2}$ flows through the anti-parallel diode $D_{2}$ of switch $S_{2}$. The leakage energy of coupled inductor is transferred to $C_{l}$ through $D_{2}$ in interval III of boost operation.

The experimental waveform of the current in diode $D_{3}$ is shown in Figure 7(c). During intervals I and II, $D_{3}$ is forward biased, and energy is transferred from $C_{1}$ to $C_{2}$. This stored energy is transferred through the diode $D_{4}$ to the output capacitor and load resistance during intervals III, IV and V as shown in Figure 7(d). The voltage and the current waveforms in the primary winding $L_{1}$ and secondary winding $L_{2}$ are shown in Figure 8(a) and Figure 8(b), respectively. The current ratio is found dependent on the external circuit and the amount of energy stored. For the parameters given in Table 3, it is observed that the voltage stress across $S_{1}$ and $S_{2}$ is less than $20.0 \mathrm{~V}$ while across $S_{3}$ and $S_{4}$ is around $80.0 \mathrm{~V}$ in boost operation.

The experimental waveforms of input current and voltage during boost operation are shown in Figure 8(c). During boost mode, input voltage across the battery is $10.8 \mathrm{~V}$ and a current of $2.5 \mathrm{~A}$ is drawn from the battery. With $50 \%$ duty ratio, the output voltage is observed as $100.2 \mathrm{~V}$ and output current is $0.25 \mathrm{~A}$ as shown in Figure 8(d). Voltage gain obtained by the BDC is 10 during boost mode of operation.

\subsection{Experimentation in buck mode of operation}

The experimental results of buck mode are presented in this section. A single-phase AC variac and diode bridge rectifier is used as a source on the HV side of the BDC. On the LV side, a rheostat is connected to perform buck operation in open loop.

Switch $S_{l}$ is not operated during the buck mode. However, the anti-parallel diode $D_{l}$ will conduct during intervals III, IV and $\mathrm{V}$. The voltage and the current waveforms of diode $D_{l}$ is observed in Figure 9(a). Diode $D_{l}$ transfers energy stored in the leakage inductance and the magnetizing inductance of the coupled inductor. Figure 9(b) shows the voltage and current waveforms of switch $S_{2}$. When $S_{2}$ is turned ON, the energy stored in $C_{l}$ transfers to the primary of the coupled inductor. $S_{2}$ remains ON during interval I and II.
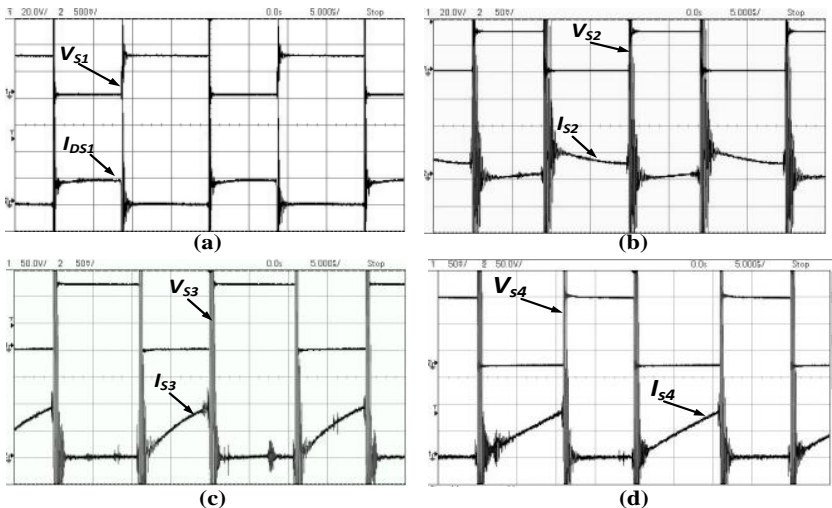

Figure 9. Steady-state waveform of switch voltage and switch current in buck mode: (a) $V_{S 1}, I_{D S 1}$; (b) $V_{S 2}, I_{S 2}$; (c) $V_{S 3}$, $I_{S 3} ;$ and (d) $V_{S 4}, I_{S 4}$

Current $I_{S 3}$ through switch $S_{3}$ and the voltage $V_{S 3}$ across switch $S_{3}$ are shown in Figure 9(c). $S_{3}$ is ON during interval IV of the buck operation. Energy transfers from $C_{2}$ to $C_{1}$ and $L_{2}$ through the switch $S_{3}$. In the buck operation, $S_{4}$ is the main controlling switch, where the duty cycle of $S_{4}$ decides the duty cycle of $S_{2}$ and $S_{3}$. Switch $S_{4}$ remains ON during interval I and 
II of the buck operation. Figure 9(d) shows the experimental waveforms of current through $S_{4}$ and voltage across $S_{4}$.

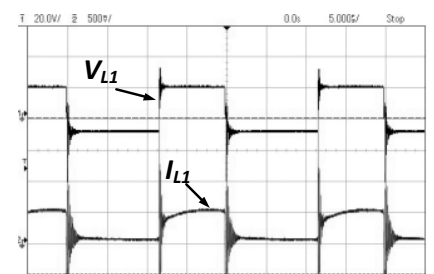

(a)

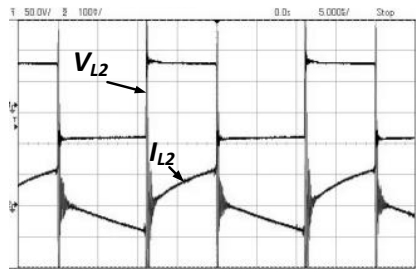

(b)

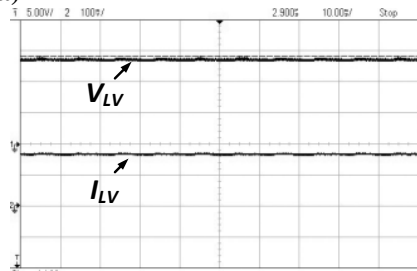

(c)

Figure 10. Steady-state waveform of voltage and current in buck mode: (a) primary winding: $V_{L l}, I_{L l}$; (b) secondary winding: $V_{L 2}, I_{L 1}$; (c) low voltage output: $V_{L V}, I_{L V}$

Figure 10(a) and Figure 10(b) show the voltage and current waveforms of coupled inductor $L_{1}$ and $L_{2}$ respectively. The coupled inductor was designed for turns ratio $n=4$ which is verified by observing the voltage magnitude across primary and secondary of the coupled inductor. Currents through these windings are not proportioned like voltages because it is dependent on the external circuit and the amount of energy stored. The voltage across load resistance $V_{L V}$ and current through load resistance $I_{L V}$ are shown in Figure 10(c). Load current and voltage both are constant and ripple free.

It is observed that the voltage stress across $S_{1}$ and $S_{2}$ is around $30 \mathrm{~V}$ while across $S_{3}$ and $S_{4}$ is $120 \mathrm{~V}$ in buck operation. For the input voltage of $140 \mathrm{~V}$, output of $13.4 \mathrm{~V}$ is observed for $50 \%$ duty ratio. Hence, an approximate gain of $1 / 10$ is achieved experimentally. The buck mode of operation of the $\mathrm{BDC}$ is validated by this experiment.

Table 3. Lead-acid battery charging parameters

\begin{tabular}{cc}
\hline Parameter & Value \\
\hline \multicolumn{2}{c}{ Input Parameters } \\
Supply Voltage & $140 \mathrm{~V}$ \\
Max Input Current & $3 \mathrm{~A}$ \\
Switching Frequency & $50 \mathrm{kHz}$ \\
\multicolumn{2}{c}{ Output Parameters } \\
Max Battery Voltage $14.4 \mathrm{~V}$ \\
Max Battery Current & $11.25 \mathrm{~A}$ \\
\hline
\end{tabular}

\subsection{Battery charging application}

In this section, the BDC is operated to charge a lead-acid battery. The selected pre-set voltage level charging scheme for the six-cell battery is as shown in Figure 11(a). Block diagram of charging voltage regulator is shown in Figure 11(b).

The battery voltage $V_{b a t}$ and the battery current $I_{b a t}$ is sensed using the DC sensor card. Battery voltage is compared with the reference battery voltage. The error is given to a PI controller to generate a reference battery current which is passed through the saturation block to limit it to less than rated charging current. This reference battery current is compared with actual battery current and the error is given to another PI controller.
According to the error, the PI controller adjusts the duty cycle of switching pulse which is generated by the advanced timer (TIM1) of STM32F407VG. The battery charging parameters for lead-acid battery is shown in Table 3 .

The programmed values for different phases are given below:

(1) Constant Current Phase: Here, $10 \mathrm{~V} \leq V_{b a t}<14 \mathrm{~V}$ and the constant charging current is $1.5 \mathrm{~A}$.

(2) Constant Voltage Phase: Here, $V_{b a t}=14 \mathrm{~V}$

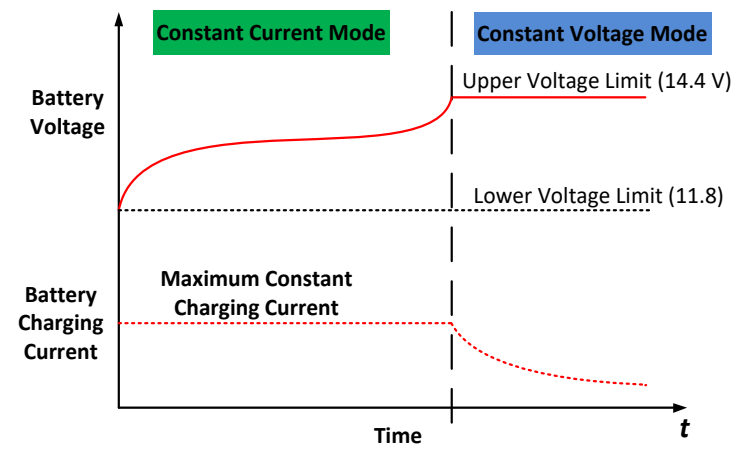

(a)

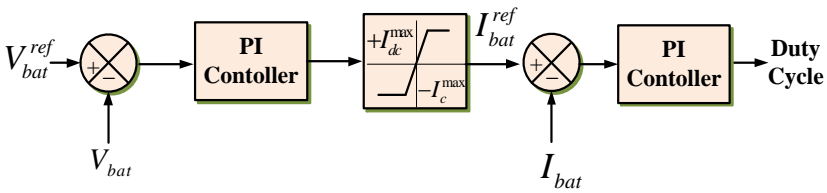

(b)

Figure 11. Lead-acid battery charging: (a) preset voltage level charging scheme for the six-cell battery; (b) block diagram of charging controller
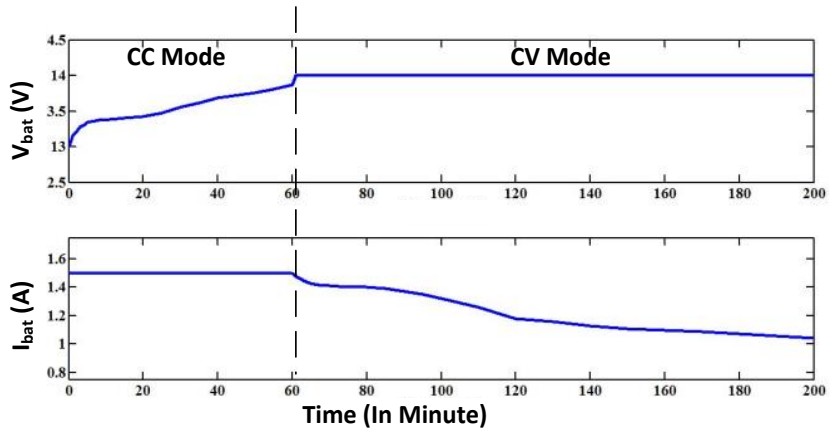

(a)

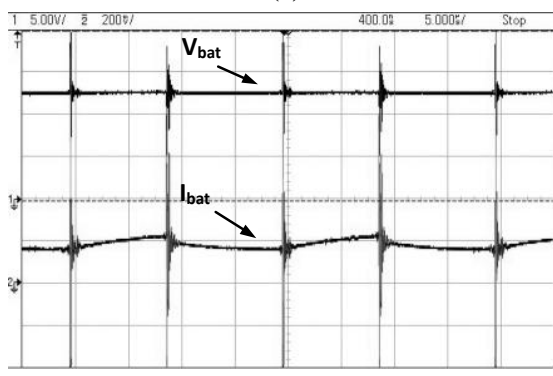

(b)

Figure 12. Lead-acid battery charging experiment results: (a) Graph of experimental results, $V_{b a t} v s t$ and $I_{b a t} v s t$; and

(b) steady-state waveform of $V_{b a t}$ and $I_{b a t}$.

The experimental results for a $12 \mathrm{~V} 42$ Ah lead-acid battery are shown in Table 4. In this table, input voltage, input current, output voltage, and output current are noted down with respect to time. The output voltage is battery voltage $V_{b a t}$ and the 
output current is battery charging current $I_{b a t}$. Initially, due to the battery discharging, battery voltage is less than the pre-set voltage. In this interval, the BDC starts charging through a constant current of $1.5 \mathrm{~A}$. Once the battery voltage reaches the pre-set voltage of $14 \mathrm{~V}$, the BDC starts charging at a constant voltage of $14.4 \mathrm{~V}$ and the current starts reducing. The results of Table 4 are plotted and presented in Figure 12(a). The steady-state waveform of charging voltage and current are depicted in Figure 12(b).

The performance of the BDC is observed for boost, buck, and the battery charging operations. Experimentally, the voltage gain is verified as $1 / 10$ in buck mode and 10 in boost mode of operation. During buck mode, the voltage stress on switches $S_{1}$ and $S_{2}$ is $30 \mathrm{~V}$ and voltage stress on switches $S_{3}$ and $S_{4}$ is $120 \mathrm{~V}$. During boost mode, the voltage stress on switches $S_{1}$ and $S_{2}$ is $20 \mathrm{~V}$ and voltage stress on switches $S_{3}$ and $S_{4}$ is $80 \mathrm{~V}$.

The CCCV method is used to charge a $12 \mathrm{~V} 42$ Ah lead-acid battery. During the charging experiment, the lower voltage battery $(12 \mathrm{~V})$ is charged effectively from the high voltage of source of $140 \mathrm{~V}$ utilizing the designed BDC. This developed charging circuit can also be used with lithium-ion batteries requiring constant current and constant voltage charging. The use of SiC MOSFET and soft switching in the converter makes the losses of the converter least possible. The $50 \mathrm{kHz}$ high switching frequency and SiC MOSFET makes the size of the converter compact. Also, the use of general-purpose microcontroller makes the converter cost effective.

Table 4. Lead-acid battery charging test results

\begin{tabular}{|c|c|c|c|c|}
\hline $\begin{array}{c}\text { Time } \\
\text { (Minute) }\end{array}$ & $\begin{array}{c}\text { Input } \\
\text { Voltage } \\
\text { (V) }\end{array}$ & $\begin{array}{l}\text { Input } \\
\text { Current } \\
\text { (A) }\end{array}$ & $\begin{array}{c}\text { Output } \\
\text { Voltage } \\
\text { (V) }\end{array}$ & $\begin{array}{l}\text { Output } \\
\text { Current } \\
\text { (A) }\end{array}$ \\
\hline 0 & 140 & 0.180 & 13.00 & 1.50 \\
\hline 1 & 140 & 0.180 & 13.15 & 1.50 \\
\hline 2 & 140 & 0.180 & 13.20 & 1.50 \\
\hline 3 & 140 & 0.180 & 13.27 & 1.50 \\
\hline 4 & 140 & 0.180 & 13.30 & 1.50 \\
\hline 5 & 140 & 0.180 & 13.34 & 1.50 \\
\hline 8 & 140 & 0.180 & 13.37 & 1.50 \\
\hline 11 & 140 & 0.180 & 13.38 & 1.50 \\
\hline 15 & 140 & 0.180 & 13.40 & 1.50 \\
\hline 25 & 140 & 0.180 & 13.47 & 1.50 \\
\hline 30 & 140 & 0.180 & 13.56 & 1.50 \\
\hline 35 & 140 & 0.180 & 13.62 & 1.50 \\
\hline 40 & 140 & 0.180 & 13.69 & 1.50 \\
\hline 50 & 140 & 0.180 & 13.81 & 1.50 \\
\hline 55 & 140 & 0.180 & 13.87 & 1.50 \\
\hline 60 & 140 & 0.180 & 14.00 & 1.50 \\
\hline 63 & 140 & 0.180 & 14.00 & 1.45 \\
\hline 65 & 140 & 0.180 & 14.00 & 1.43 \\
\hline 67 & 140 & 0.175 & 14.00 & 1.42 \\
\hline 70 & 140 & 0.175 & 14.00 & 1.41 \\
\hline 75 & 140 & 0.180 & 14.00 & 1.40 \\
\hline 80 & 140 & 0.180 & 14.00 & 1.40 \\
\hline 85 & 140 & 0.175 & 14.00 & 1.39 \\
\hline 90 & 140 & 0.175 & 14.00 & 1.37 \\
\hline 95 & 140 & 0.175 & 14.00 & 1.35 \\
\hline 100 & 140 & 0.175 & 14.00 & 1.32 \\
\hline 110 & 140 & 0.170 & 14.00 & 1.26 \\
\hline 130 & 140 & 0.160 & 14.00 & 1.16 \\
\hline 150 & 140 & 0.150 & 14.00 & 1.11 \\
\hline 180 & 140 & 0.135 & 14.00 & 1.07 \\
\hline 300 & 140 & 0.130 & 14.00 & 1.04 \\
\hline
\end{tabular}

\section{CONCLUSION}

In this paper, a coupled inductor based BDC having inherent soft-switching capability is presented for the application of battery charging. The complete design of circuit parameters including coupled inductor have been presented. The results have verified the capability of the proposed converter in boost, buck, and battery charging modes. The features have been validated by the experimental results using a laboratory-scale $500 \mathrm{~W}$ prototype. This battery charger is expected to work well in high-power applications where the storage elements are required to be integrated to existing power and electrical systems such as the microgrid, standalone renewable energy systems, elevators, etc.

\section{REFERENCES}

[1] Jabri, I., Bouallegue, A., Ghodbane, F. (2019). Analysis and modelling of wireless battery charger. International Journal of Power Electronics, 10(3): 212-235. https://doi.org/10.1504/IJPELEC.2019.099338

[2] Xiao, W., Ozog, N., Dunford, W.G. (2007). Topology study of photovoltaic interface for maximum power point tracking. IEEE Transactions on Industrial Electronics, 54(3): 1696-1704. https://doi.org/10.1109/TIE.2007.894732

[3] Yadlapalli, R.T., Kotapati, A. (2020). Modelling, design and implementation of quadratic buck converter for low power applications. International Journal of Power Electronics, 11(3): 322-338. https://doi.org/10.1504/IJPELEC.2020.106224

[4] Yang, M.J., Jhou, H.L., Ma, B.Y., Shyu, K.K. (2009). A cost-effective method of electric brake with energy regeneration for electric vehicles. IEEE Transactions on Industrial Electronics, 56(6): 2203-2212. https://doi.org/10.1109/TIE.2009.2015356

[5] Baughman, A.C., Ferdowsi, M. (2008). Double-tiered switched-capacitor battery charge equalization technique. IEEE Transactions on Industrial Electronics, 55(6): 2277-2285. https://doi.org/10.1109/TIE.2008.918401

[6] Benlahbib, B., Bouchafaa, F., Bouarroudj, N., Mekhilef, S. (2019). Fractional order PID controller for DC link voltage regulation in hybrid system including wind turbine-and battery packs-experimental validation. International Journal of Power Electronics, 10(3): 289313. https://doi.org/10.1504/IJPELEC.2019.099346

[7] Fapi, C.B.N., Wira, P., Kamta, M., Colicchio, B. (2020). Voltage regulation control with adaptive fuzzy logic for a stand-alone photovoltaic system. European Journal of Electrical Engineering, 22(2): 145-152. https://doi.org/10.18280/ejee.220208

[8] Jayaraju, G., Rao, G.S. (2019). A new optimized ANN algorithm based single phase grid connected PV-wind system using single switch high gain DC-DC converter. European Journal of Electrical Engineering, 21(4): 373381. https://doi.org/10.18280/ejee. 210405

[9] Katuril R., Gorantla S. (2018). Comparative analysis of controllers for a smooth switching between battery and ultracapacitor applied to E-vehicle. European Journal of Electrical Engineering, 20(1): 47-75. https://doi.org/10.3166/EJEE.20.47-75

[10] Katuril R., Gorantla S. (2018). Performance analysis of hybrid controller for automatic switching between 
energy sources of hybrid energy storage system. European Journal of Electrical Engineering, 20(5-6): 617-630. https://doi.org/10.3166/EJEE.20.617-630

[11] Kazimierczuk, M.K. (2015). Pulse-Width Modulated DC-DC Power Converters. John Wiley \& Sons.

[12] Ortúzar, M., Moreno, J., Dixon, J. (2007). Ultracapacitor-based auxiliary energy system for an electric vehicle: Implementation and evaluation. IEEE Transactions on Industrial Electronics, 54(4): 2147-2156. https://doi.org/10.1109/TIE.2007.894713

[13] Forouzesh, M., Siwakoti, Y.P., Gorji, S.A., Blaabjerg, F., Lehman, B. (2017). Step-up DC-DC converters: a comprehensive review of voltage-boosting techniques, topologies, and applications. IEEE Transactions on Power Electronics, 32(12): 9143-9178. https://doi.org/10.1109/TPEL.2017.2652318

[14] Liu, H., Hu, H., Wu, H., Xing, Y., Batarseh, I. (2016). Overview of high-step-up coupled-inductor boost converters. IEEE Journal of Emerging and Selected Topics in Power Electronics, 4(2): 689-704. https://doi.org/10.1109/JESTPE.2016.2532930

[15] Sedaghati, F., Haghmaram, R. (2020). A modular DCDC converter with zero voltage switching capability. International Journal of Power Electronics, 11(1): 56-73. https://doi.org/10.1504/IJPELEC.2020.103950

[16] Tofoli, F.L., de Castro Pereira, D., de Paula, W.J., Júnior, D.D.S.O. (2015). Survey on non-isolated high-voltage step-up dc-dc topologies based on the boost converter. IET Power Electronics, 8(10): 2044-2057. https://doi.org/10.1049/iet-pel.2014.0605

[17] Wu, T.F., Yang, J.G., Kuo, C.L., Wu, Y.C. (2013). Softswitching bidirectional isolated full-bridge converter with active and passive snubbers. IEEE Transactions on Industrial Electronics, 61(3): 1368-1376. https://doi.org/10.1109/TIE.2013.2262746

[18] Yang, J.W., Do, H.L. (2013). High-efficiency bidirectional DC-DC converter with low circulating current and ZVS characteristic throughout a full range of loads. IEEE Transactions on Industrial Electronics, 61(7): 3248-3256. https://doi.org/10.1109/TIE.2013.2279370

[19] Wu, T.F., Chen, Y.C., Yang, J.G., Kuo, C.L. (2010). Isolated bidirectional full-bridge DC-DC converter with a flyback snubber. IEEE Transactions on Power Electronics, 25(7): 1915-1922. https://doi.org/10.1109/TPEL.2010.2043542

[20] Zhang, F., Yan, Y. (2008). Novel forward-flyback hybrid bidirectional DC-DC converter. IEEE Transactions on Industrial Electronics, 56(5): 1578-1584. https://doi.org/10.1109/TIE.2008.2009561

[21] Houreh, A.B., Ershadi, M.H. (2019). Fuzzy control of the push-pull fly-back three-phase DC-DC converter. Modelling, Measurement and Control A, 92(1): 1-6. https://doi.org/10.18280/mmc_a.920101

[22] Amjadi, Z., Williamson, S.S. (2009). A novel control technique for a switched-capacitor-converter-based hybrid electric vehicle energy storage system. IEEE Transactions on Industrial Electronics, 57(3): 926-934. https://doi.org/10.1109/TIE.2009.2032196

[23] Hsieh, Y.P., Chen, J. F., Yang, L.S., Wu, C.Y., Liu, W.S. (2013). High-conversion-ratio bidirectional DC-DC converter with coupled inductor. IEEE Transactions on Industrial Electronics, 61(1): 210-222. https://doi.org/10.1109/TIE.2013.2244541

[24] Shreelakshmi, M.P., Das, M., Agarwal, V. (2018). Design and development of a novel high voltage gain, high-efficiency bidirectional DC-DC converter for storage interface. IEEE Transactions on Industrial Electronics, 66(6): 4490-4501. https://doi.org/10.1109/TIE.2018.2860539

[25] Garcia-Valle, R., Lopes, J.A.P. (Eds.). (2012). Electric Vehicle Integration into Modern Power Networks. Springer Science \& Business Media.

\section{NOMENCLATURE}

$\begin{array}{ll}a & \text { Cross-sectional area of conductor, } \mathrm{mm}^{2} \\ A_{w} & \text { Window Area of Core, } \mathrm{mm}^{2} \\ A_{c} & \text { Cross-sectional area of core, } \mathrm{mm}^{2} \\ \text { BDC } & \text { Bidirectional DC-DC Converter } \\ \text { CCM } & \text { Continuous Current Mode } \\ \text { CCCV } & \text { Constant Current Constant Voltage } \\ D & \text { Dimensionless duty ratio } \\ \text { DCM } & \text { Discontinuous Current Mode } \\ f_{s w} & \text { switching frequency, Hz } \\ I_{b a t} & \text { Battery current, A } \\ J & \text { Current density, A/mm }{ }^{2} \\ L_{c r i t} & \text { Critical value of inductance, } \mathrm{H} \\ l_{g} & \text { Air gap length } \\ l_{m} & \text { Magnetic path length } \\ L_{m} & \text { Magnetizing inductance, } \mathrm{H} \\ n & \text { Dimensionless turns ratio } \\ N_{l} & \text { Turns of transformer HV side } \\ N_{2} & \text { Turns of transformer LV side } \\ \mathrm{PI} & \text { Proportional Integral } \\ R_{L V} & \text { Resistance of low voltage side, } \Omega \\ \mathrm{SiC} & \text { Silicon Carbide } \\ \mathrm{RMS} & \text { Root Mean Square } \\ T_{S} & \text { Switching time period, s } \\ V_{b a t} & \text { Battery voltage, V } \\ \mathrm{ZVS} & \text { Zero Voltage Switching } \\ & \end{array}$

\section{Greek symbols}

$\begin{array}{ll}\Lambda & \text { Permeance } \\ \mu_{r} & \text { Relative permeance }\end{array}$

